\title{
REGIMES DE ORDENAÇÃO ESPACIAL NO BRASIL: a fusão de neoliberalismo, populismo de esquerda e visões modernistas na urbanização de favelas no Recife ${ }^{1}$
}

\author{
Monique Nuijten* \\ Martijn Koster** \\ Pieter de Vries ** \\ Augusto Antonio Campelo Cabral ***
}

\begin{abstract}
Este artigo mostra como os regimes de ordenação espacial são produzidos pela junção de três forças: neoliberalismo, políticas de esquerda e visões modernistas. Ele focaliza o PROMETRÓPOLE, um programa de urbanização em Recife. Nesse programa, a dimensão neoliberal é manifesta na ideia de que o Estado, as empresas privadas e os cidadãos são responsáveis conjuntamente pela construção do espaço urbano. Além disso, espera-se que os beneficiários sejam cidadãos autônomos, assumindo a responsabilidade por seu novo ambiente. A dimensão política de esquerda promove, através de procedimentos participativos, o envolvimento dos moradores no projeto. A adoção de uma estética modernista exige que os moradores usem o espaço segundo os padrões da "civilização moderna". No entanto, a pesquisa mostra que esse regime destoa dos modos de vida da população. Além disso, os procedimentos participativos fracassam na atribuição de qualquer influência real sobre os moradores. No final, os residentes reconstroem drasticamente seus novos conjuntos habitacionais, reapropriando-se do espaço urbano e contestando o regime que lhes foi imposto.

PAlavras-Chave: Urbanização de favelas. Espaço urbano. Participação. Neoliberalismo. Socialismo.
\end{abstract}

\section{INTRODUÇÃO: a fusão de três abor- dagens na ordenação espacial urbana}

Este artigo discute como, na cidade brasileira do Recife, projetos de urbanização de favelas são guiados por um regime de ordenação espacial que combina o neoliberalismo com o populismo de esquerda, enquanto se mantém enraizado em uma abordagem modernista para o planejamento da cidade. Sob a bandeira da democratização, o governo do Partido dos Trabalhadores (PT) defendia a participação popular, bem como a visão de que os pobres devem

* Universidade de Wageningen. Departamento de Ciências Sociais.

Hollandseweg 1, 6706 KN. Wageningen - Holanda.

monique.nuijten@wur.nl

** Radboud University. Departamento de Antropologia e Estudos de Desenvolvimento.

Thomas van Aquinostraat 6, 6525 GD. Nijmegen - Holanda.m.koster@maw.ru.nl

*** Universidade de Wageningen. Departamento de Ciências Sociais.

Hollandseweg 1, 6706 KN. Wageningen - Holanda. pieter. devries@wur.nl

**** Secretaria de Educacão de Pernambuco. Escola de Referência em Ensino Médio Santa Paula Frassinetti Rua Gomes Pacheco, s/n. Espinheiro. Cep: 52.021-060. Recife - Pernambuco - Brasil. augustoceegp@yahooo.com.br

${ }^{1}$ Tradução do artigo "Regimes of spatial ordering in Brazil: assumir a responsabilidade por suas próprias vidas e se comportar como bons cidadãos. Essa visão mais neoliberal da cidadania também vem à tona em programas de renovação urbana. Como Caldeira e Holston (2005, p. 409) observam, democratização e neoliberalismo se entrelaçaram de maneira paradoxal na produção do espaço urbano no Brasil.

O termo neoliberalismo é frequentemente utilizado como uma conceituação abrangente das tendências atuais nos campos político, econômico e social, que se caracteriza pela importância atribuída aos mercados abertos, não regulamentados, com diminuição da intervenção estatal, privatização, recuo das instituições assistencialistas e social-coletivistas e cortes nos serviços públicos. (Brenner; Theodore, 2002; Fuller; Geddes, 2008; Peck; neoliberalism, leftist populism and modernist aesthetics in slum upgrading in Recife", originalmente publicado em inglês na revista Singapore Journal of Tropical Geography, Singapura, v. 33, n. 2, p. 157-170, 2012. Republicado em português com permissão de John Wiley \& Sons, Inc. Esta pesquisa foi financiada por uma concessão VIDI $\left(\mathrm{n}^{\circ}\right.$ 452-05-365) de NWO, a Netherlands Organization for Scientific Research. Martijn Koster agradece ao ERC pelo auxílio à pesquisa (n. 679614). Agradecemos a Jan Bitoun, Edvânia Tôrres Aguiar Gomes e Mônica Valéria dos Santos Cabral por seu inestimável apoio e frutíferas discussões. 
Tickell, 2002). Juntamente com essa forma "conservadora" de neoliberalismo, alguns autores argumentam que um "neoliberalismo estendido", mais sutil, dominou desde os meados dos anos 1990, caracterizado pela criação de regulamentos e instituições que apoiam o funcionamento do livre mercado e a participação dos agentes não governamentais em parcerias público-privadas (Aguirre; Eick; Reese, 2006; Peck; Tickell, 2002).

Os projetos de urbanização de favelas no Recife certamente não seguem um modelo do neoliberalismo conservador. Pelo contrário, o PT - que era responsável pela gestão do município do Recife e pelo governo federal - enfatizava o papel assistencialista do Estado e reforçava várias formas de apoio financeiro, como o Bolsa Família, um programa de assistência social que prevê transferências diretas de dinheiro aos pobres. Na urbanização de favelas, a ideologia neoliberal se manifesta na importância dada à participação, à instrução e ao apoio da população que está sendo reassentada. O projeto de melhoria de favelas, em nosso estudo, é um exemplo claro do chamado "neoliberalismo estendido”. Em consonância com as tendências neoliberais, o município do Recife solicitou propostas para as muitas tarefas de construção dentro do projeto. Depois de uma competição de licitação aberta, os contratos foram concedidos $\infty$ às empresas que fizeram as melhores ofertas. จे Curiosamente, o setor privado não só foi forçado a competir mais intensamente para ganhar ฮี encomendas, mas também foi convidado a deనొ senvolver programas sociais para a população 蚛 reassentada. Esse é um novo campo de trabai. lho para a maioria das empresas de construção. $\therefore$ Aqui, vemos um modo neoliberal de governo, i no qual as empresas privadas são responsáveis por tarefas que, no passado, eram consideradas de responsabilidade do Estado.

Não é nosso objetivo, com este trabalho, lançar luz sobre um caso que ilustra o "rastejamento global do neoliberalismo como governamentalidade totalizante" (Schwegler, 2008, p. 684), mas, sim, expor o "neoliberalismo real- mente existente" (Brenner; Theodore, 2002, p. 351), que se manifesta em um projeto de renovação urbana particular e é sentido por parte dos pobres da cidade, que são seus "beneficiários". As políticas neoliberais são sempre "definidas pelo legado herdado de quadros institucionais, regimes de políticas, práticas reguladoras e lutas políticas" (Brenner; Theodore, 2002, p.) e, por isso, muitas vezes, levam a formas híbridas de neoliberalismo (Peck; Tickell, 2007). No caso do Recife, mostramos como noções neoliberais de responsabilidades públicas e privadas e cidadania autônoma mesclaram-se com ideologias de esquerda, como a valorização da decisão participativa, e visões modernistas sobre o uso do espaço urbano. Juntas, elas formam um regime de ordenação espacial cujos efeitos são de longo alcance sobre a população das favelas.

A cidade do Recife possui um histórico de protestos coletivos contra o regime ditatorial anterior (1964-1984). Após o retorno à democracia, poderes de esquerda se tornaram influentes no governo municipal. O Recife é conhecido pelas suas formas avançadas de participação popular e adoção do orçamento participativo na gestão municipal. Embora tenha sido apenas em 2002 que o PT venceu as eleições nacionais pela primeira vez, o partido já havia triunfado em Recife em 2000 e permaneceu no poder desde então. Curiosamente, pode-se dizer que, sob a regência do PT, a cidadania adquiriu características neoliberais. Mais significativamente, a participação direta e individual dos cidadãos é preferida às formas mais coletivas de representação. O governo do PT, em Recife, argumentava que, além dos comitês participativos constituídos pelo Estado, as organizações populares estavam desatualizadas, pois cada cidadão pode, individualmente, responsabilizar o Estado (ver, por exemplo, Etapas, 2003). ${ }^{2}$ Essa noção de cidadania faz com que seja um dever da população cuidar de si mesma e se comportar como "bons cidadãos” em relação ao Estado (Holston, 2008).

${ }^{2}$ No Recife, as organizações populares têm um papel marginal no orçamento participativo. 
A dimensão final que determina os projetos de urbanização de favelas no Recife é a influência do "alto modernismo", a aspiração de melhorar a condição humana através de "uma engenharia vasta e racional de todos os aspectos da vida social" (Scott, 1998, p. 88). Como Scott argumenta, são normalmente progressistas que chegaram ao poder com uma crítica global da sociedade existente, que se envolvem em grandes projetos modernistas para transformar os hábitos, o trabalho, os padrões de vida e de conduta moral das pessoas (Scott, 1998). As casas novas e idênticas, as ruas asfaltadas e os cursos d'água canalizados transmitem a promessa de ordem e progresso, em contraste com habitações desorganizadas, situadas nas margens e ribanceiras de rios, que representam o atraso e a decadência. Como mostraremos, muitos moradores de favelas foram atraídos pela ideia de modernidade do projeto, que pode gerar fortes aspirações para um futuro melhor (Berman, 1982). No entanto, eles não gostaram da proibição de adaptar as casas às suas próprias necessidades.

Este artigo enfoca o Jacarezinho, a primeira favela que foi demolida como parte do Programa PROMETRÓPOLE, um projeto de urbanização financiado pelo Banco Mundial que visava a melhorar a infraestrutura urbana e envolvia a demolição de barracos e o reassentamento da população afetada. Os moradores do Jacarezinho receberam novas casas perto de onde viviam anteriormente. Contudo a concepção modernista do regime de relocação entrou em confronto com os meios de vida dos pobres. As novas casas eram muito pequenas, não permitiam a realização de suas atividades cotidianas e, em função do ambiente violento, não estavam bem protegidas.

Em resposta, a população começou a se reapropriar do espaço de acordo com suas necessidades e desejos. Os representantes do Programa viram esse processo como uma traição ao projeto e afirmavam que aquelas pessoas não estavam prontas para a civilização. Para ensinar os pobres a se tornarem cidadãos adequados, foi oferecido um treinamento às famílias reassentadas, que foram visitadas por agentes da assistência social. Aqui, vemos como o liberalismo estendido "envolve políticas sociais de intervenção e iniciativas públicas e privadas que são paternalistas e punitivas", pois buscam disciplinar, criminalizar e controlar os grupos sociais marginalizados (Aguirre; Eick; Reese, 2006, p. 2). Vemos o confronto entre o projeto oficial e seu funcionamento alterado pela população-alvo, como uma consequência da discrepância entre o regime do projeto de ordenação espacial, implantado pelo neoliberalismo, pela ideologia de esquerda e pelo modernismo, de um lado, e, de outro, a lógica dos pobres da cidade, tentando arduamente ganhar a vida diária.

O artigo é baseado em pesquisa etnográfica realizada em diversos períodos, entre 2003 e 2011. ${ }^{3}$ Faremos, inicialmente, uma breve introdução sobre o Recife e suas favelas, e forneceremos informações sobre o PROMETRÓPOLE e sua primeira área-alvo, a favela do Jacarezinho, localizada às margens do riacho do mesmo nome, no bairro de Campina do Barreto, nos limites com do bairro do Arruda. Depois, mostraremos como o projeto apresentava um regime de ordenação espacial no qual as três dimensões apresentadas acima se fundiram. Finalmente, discutiremos os efeitos do projeto sobre as condições de vida dos habitantes da favela e como a população-alvo começou a se reapropriar do espaço público e privado, contra a lógica do projeto.

3 Sobre os autores dessa pesquisa: a primeira visitou a área durante vários meses a cada ano, desenvolvendo suas pesquisas etnográficas; o segundo, viveu na área durante 18 meses e voltou várias vezes desde então; o terceiro, foi morador no bairro vizinho desde o nascimento e do bairro onde se encontra localizada a favela desde 1989, sendo essa comunidade objeto de estudo em suas pesquisas de especialização, mestrado e doutorado. Foram feitas observações e realizadas entrevistas com uma série de participantes, incluindo membros da população local, famílias reassentadas, pessoas à espera de uma nova casa, líderes comunitários, políticos, funcionários das empresas de construção e representantes do projeto municipal, em diferentes níveis. Ao longo dos anos, participamos de diversas reuniões, bem como de assembleias de políticos e encontros locais de moradores de favelas. Além disso, coletamos e analisamos documentos políticos, diretrizes de projetos, desenhos, mapas, resultados de pesquisa e recortes de jornais relacionados ao PROMETROPOLE. 
O CONTEXTO DA URBANIZAÇÃO DE FAVELAS NO RECIFE

A cidade do Recife é a capital do Estado de Pernambuco. Sua paisagem urbana apresenta bairros de classe média, modernos e altamente protegidos, situados ao lado de assentamentos carentes, conhecidos como favelas. O município do Recife possui 1.472.202 habitantes (Ibge, 2010). Entre 1939 e 1978, as casas de mais de metade de sua população estavam situadas em favelas (Sousa, 2003). Números mais recentes mostram que $60 \%$ de sua população estão vivendo em assentamentos precários (Maia, 1995), ocupando apenas $14 \%$ da área total da cidade (Souza, 2001). As favelas tendem a se localizar em morros ou na proximidade de cursos d'água, pântanos ou manguezais.

Um tipo característico de barraco no Recife é a palafita: um barraco sobre estacas acima d'água. As palafitas são tidas como imagem de pobreza, e são marcadas por sentimentos de vergonha. A população de classe média do Recife se sente envergonhada, pois os cartões postais de sua cidade ilustram as palafitas adjacentes às rodovias e seus arranha-céus. $\mathrm{O}$ projeto municipal "Recife sem palafitas" deve garantir que os futuros cartões postais mostrem uma cidade moderna, sem esses símbolos de pobreza.

Não existe um acordo uniforme sobre a definição de uma favela. Várias definições são utilizadas por diferentes institutos e seus representantes, e elas também não coincidem com as utilizadas pelos moradores dessas áreas. No Recife, a maioria dos moradores de favelas não $\dot{\mathrm{i}}$ gosta, dada a sua conotação pejorativa, do termo favela como um rótulo para sua comunidade. Para os políticos, apesar de suas diferenças internas, as características geralmente aceitas para as favelas incluem a ocupação ilegal de terras e habitações construídas pelos próprios moradores, com materiais baratos e reciclados. As favelas também carecem de infraestrutura básica, como água encanada, esgoto, drenagem e coleta de lixo, apesar de os habitantes usa- rem ilegalmente água e eletricidade a partir do sistema oficial. Inicialmente, os barracos tendem a ser construídos de madeira, plástico e papelão, e possuem pisos de terra. Numa fase posterior, podem ser aumentados e reforçados com tijolos, cimento, concreto e telhas. A diversidade de moradias de uma favela reflete a diferenciação socioeconômica de sua população e a variedade temporal de sua ocupação.

Nas áreas mais pobres das favelas, encontram-se "os fatos brutais da pobreza, marginalização e morte social” (Scheper-Hughes; Bourgois, 2003, p. 15). A vida na favela é caracterizada por muitos problemas: fome, pobreza, doenças como HIV/AIDS, desemprego, prostituição, violência doméstica e violência relacionada ao tráfico de drogas (Alvito, 2001; Dalsgaard, 2004; Goldstein, 2003).

Para os que chegam primeiro, as favelas fornecem a única possibilidade de adquirir uma habitação na cidade: a terra é gratuita e não têm de pagar por serviços públicos. Após algum tempo, o terreno ocupado e os barracos adquirem um valor de mercado e podem ser vendidos ou alugados para os recém-chegados. A depender do ponto de vista, esses assentamentos constituem "problemas" ou representam "soluções” (Perlman, 1976, p. 7). Para os pobres, os barracos são uma solução. No entanto, viver em favelas perto de um rio traz aspectos problemáticos, como a ausência de drenagem e esgotos, e as inundações frequentes que destroem os barracos e levam a graves riscos de saúde.

Desde sua primeira aparição na década de 1930, as favelas têm sido vistas como um problema incontrolável para os urbanistas (Correia, 1999; Perlman, 1976; Valladares, 2000). Algumas variedades de programas foram introduzidas para resolver esse problema crescente. Para o governo e para as classes média e alta, é um incômodo que as favelas estejam geralmente localizadas em áreas com alto valor econômico e que essa "mancha de miséria" arruíne a imagem de modernidade. Com relação à infraestrutura urbana, favelas construídas em rios 
e outros cursos d'água dificultam a circulação da água e causam inundações. A falta de sistemas de esgoto e drenagem provoca riscos para a saúde não só para a população das favelas, mas para toda a cidade. Como último aspecto, as favelas são vistas como esconderijos para criminosos e espaços para outras práticas, e como áreas perigosas para representantes do governo e para a polícia. Como tal, há muitas razões para o governo, além de "ajudar os pobres", participar de projetos que visem à modernização e à remoção de favelas.

O Recife viu inúmeros programas destinados a erradicar as favelas e à construção de habitações públicas (ver Koster; Nuijten, 2012). Juntamente com programas de remoção de favelas, inúmeras iniciativas e alternativas têm sido desenvolvidas para reconhecer os direitos dos moradores das favelas à terra que ocupam e melhorar a infraestrutura nos locais. Na década de 1980, áreas urbanas consideradas ilegais foram alvos de intervenções do Estado, relativas à prestação de serviços sociais e à legalização de propriedade. O objetivo era proteger essas áreas da especulação imobiliária. No Recife, isso foi realizado através de um sistema pioneiro de leis, o Plano de Regularização das Zonas Especiais de Interesse Social (PREZEIS), um produto conjunto do município e de diversos movimentos sociais (Assies, 1992; Fase; Cendhec; Urb, 1997; Souza, 2001, 2004). Embora a legalização de áreas ocupadas irregularmente tenha sido muito prolongada, a remoção de favelas do Recife tem sido um processo inexorável, a par da construção de conjuntos habitacionais para os pobres.

O PROMETRÓPOLE é outro exemplo desse desenvolvimento. Trata-se de um programa de infraestrutura que cobre áreas de baixa renda na Região Metropolitana do Recife (World bank, 2003) e, como tal, é um projeto importante para a melhoria da infraestrutura física e social da cidade (Condepe-Fidem, 2007). Ele prioriza áreas junto a canais, que podem ser caracterizadas pela pobreza e por um ambiente natural vulnerável. Juntamente com a melhoria dos sistemas de esgoto e drenagem, os barracos situados nas margens dos rios e de outros cursos d'água foram removidos e a população transferida para novas unidades habitacionais. Dessa forma, o projeto visava, simultaneamente, a melhorar o controle da água, restaurar a qualidade do meio ambiente natural e reduzir a pobreza. O projeto foi implementado por meio do governo do Estado de Pernambuco e dos municípios vizinhos do Recife e Olinda, que, juntos, levantaram US\$ 38 milhões de fundos. O restante do trabalho foi financiado por um empréstimo de US\$ 46 milhões do Banco Mundial (World bank, 2003). Após anos de negociações, os contratos foram assinados em abril de 2003, e as primeiras casas para os moradores da favela do Riacho do Jacarezinho foram entregues em abril de 2008.

\section{IMPLEMENTAÇÃO DO PROJETO E A CONFUSÃO ENTRE O PÚBLICO E O PRIVADO}

O PROMETRÓPOLE começou em Jacarezinho, uma favela construída ao longo de um pequeno riacho no limite da Comunidade Chão de Estrelas localizado na parte norte do Recife, perto da famosa cidade histórica de Olinda. O Jacarezinho, supostamente nomeado por causa de um filhote de jacaré que ali foi encontrado no passado, surgiu nos últimos trinta e cinco anos (Cabral, 2013). Devido à sua posição nas margens e no leito do córrego, a favela era propensa a inundações, como o eram também as estradas vicinais, em quase toda Comunidade Chão de Estrelas. Por muitos anos, as pessoas de Chão de Estrelas se queixavam às autoridades municipais sobre esse problema, exigindo a remoção dos barracos construídos no riacho. Devido a seu estado crítico em termos de problemas ambientais e de condições precárias de vida, a favela de Jacarezinho foi escolhida pela Prefeitura da Cidade do Recife, como plano piloto do projeto PROMETRÓPOLE.

Esse projeto foi implementado através 
de parceria público-privada, uma característica fundamental do neoliberalismo, defendida pelos "ganhos de eficiência e custo/benefício de envolver empresas privadas no planejamento, execução, financiamento e manutenção da infraestrutura e serviços para os pobres” (Riley; Fiori; Ramirez, 2001, p. 523). As empresas privadas concorreram nas licitações para a execução das obras de construção. Como o reassentamento das populações de favelas é uma questão politicamente muito sensível, muita atenção foi prestada ao lado social do projeto e ao envolvimento da população-alvo. Tal postura foi importante para evitar protestos, obstruções e violência. Essa "gestão social" foi vista como uma responsabilidade conjunta do governo e da empresa responsável pelas obras. Para a BAM, a construtora que ganhou o contrato para obras no Jacarezinho, engajar-se numa relação de cooperação com a população-alvo foi experiência completamente nova. A BAM era bem conhecida pela construção de estradas, mas não tinha experiência alguma com a remoção de favelas. Eles criaram um departamento social, composto por quatro assistentes sociais, dirigidas por Claudia. ${ }^{4}$ A representante municipal foi Fernanda, chefe da divisão de participação do município. Em estreita colaboração, Claudia e Fernanda organizaram formas de informar à população o curso do projeto. Elas visitavam regularmente as casas, caminhavam pelo bairro, organizavam reuniões e จे atendiam a pessoas no escritório local temporário do PROMETRÓPOLE, perto do Jacarezinho.

.ี Para a população, havia pouca distinção $\curvearrowright$ entre o Estado e a empresa privada. Seus representantes sempre apareciam um ao lado do i. outro. Foram incluídos representantes munici¿ pais diretamente responsáveis pelo PROMEiे TRÓPOLE e membros de outros departamentos ou instituições envolvidos na execução do projeto de urbanização, agentes de consultoria, arquitetos, assistentes sociais, empresários da BAM, políticos do PT e seus assistentes. Para os moradores da favela, a imagem de um grande "mutirão" público-privado foi reforça${ }^{4}$ Todos os nomes são pseudônimos. do pelo fato de que quase todos os envolvidos no projeto apoiavam os ideais políticos do PT e vestiam camisetas da mesma cor vermelha. A partir da postura da população, o "processo de hibridização entre os mercados e as sociedades" (Larner; Craig, 2005, p. 403) foi concluído.

Em março de 2007, a demolição da favela começou e, depois de aproximadamente dez dias, 200 dos cerca de 500 barracos existentes no riacho foram demolidos. Após a remoção dos barracos, o projeto começou logo a cavar um imenso canal, ladeado por duas estradas pavimentadas, tornando impossível, dessa forma, o retorno das pessoas para ocupar o leito do riacho. Eventualmente, todas as 500 casas situadas na proximidade do córrego deveriam ser demolidas. 240 famílias receberiam uma casa no conjunto habitacional novo, mas foram obrigadas a deixar a área e encontrar um alojamento temporário para o ano situado entre a demolição de seus barracos e a conclusão das casas novas. Nesse período, eles receberam uma compensação financeira mensal (auxílio-moradia) de R\$151,00 (US\$ 60), a fim de alugar um pequeno imóvel em outro local. Cerca de trinta famílias receberam compensação financeira (indenização) em lugar da nova habitação, pois suas casas eram maiores e de melhor qualidade que as casas a serem construídas no projeto. As famílias restantes, por também possuírem casas maiores, aguardaram as novas casas ou sua própria casa remodelada.

O novo conjunto habitacional está localizado a 500 metros do riacho do Jacarezinho e possui casas de dois pavimentos, em estilo dúplex, com os dormitórios na parte superior. Além dessas, há residências para idosos e portadores de necessidades especiais com dormitórios no térreo. O projeto PROMETRÓPOLE incluiu também a modernização da infraestrutura urbana na área envolvente: todo o bairro seria ligado a um sistema de esgoto e drenagem, o abastecimento de água para as casas seria melhorado e todas as ruas asfaltadas. 


\section{GOVERNO PARTICIPATIVO DE ESQUERDA E CIDADANIA NEOLI- BERAL}

O Recife é bem conhecido por seus procedimentos de Orçamento Participativo (OP), no qual a população toma parte em algumas decisões relativas a uma parte do orçamento municipal. Após o término do período de ditadura, o Brasil seguiu a tendência política mundial de enfatizar a descentralização e a autonomia local, dando origem a programas baseados na comunidade. O novo município democrático do Recife introduziu o programa Prefeitura nos Bairros. A cidade foi dividida em seis áreas Político-Administrativas, e cada uma elegeu representantes para participar das decisões políticas. Na prática, esse procedimento era "destinado a enfraquecer os 'novos' movimentos urbanos emergentes" que desafiavam a prefeitura recém-instalada por não ter feito jus às expectativas que as pessoas tinham quando "a esquerda" tomou o poder após o regime militar (Assies, 1992, p. 173).

Em 2000, o PT assumiu o poder no município do Recife. Em 2001, introduziu o OP (Cop, 2002), que é frequentemente associado a Porto Alegre (Baiocchi, 2003), embora o OP do Recife seja atualmente um dos maiores programas participativos do Brasil que visam à melhoria de infraestrutura e construção da cidadania (Leal, 2003). Várias ONGs, que tinham um papel semioficial no funcionamento da abordagem pioneira do PREZEIS - logo ofuscado pelas ideias do OP -, agora estão ligadas ao processo do OP (Etapas, 2003; OP, 2011; Teixeira et al., 2004). Grandes encontros são organizados em bairros carentes com a participação dos residentes na seleção de seus representantes locais (os delegados do OP) e das obras públicas e serviços sociais a serem executados no ano seguinte, em áreas como educação, saúde, esportes e lazer.

Central a essa abordagem participativa, argumentamos ser ela um entendimento neoliberal de cidadania, do qual o PT, como outros também têm apontado (Miguel, 2006), tem se aproximado nos últimos anos. Os cidadãos devem cooperar com os procedimentos oficiais de participação (Bitoun et al., 2002; Leite, 2007) e estabelecer um relacionamento individual com os órgãos estaduais. No PROMETRÓPOLE, isso se tornou manifesto na predominância da participação individual dos cidadãos sobre as formas mais coletivas que existiam no passado. Um manual de participação especial foi elaborado pelo Banco Mundial e pela prefeitura do Recife. Um dos requisitos estabelecidos no manual é a formação de novos comitês locais de supervisão para acompanhar a concepção e a implementação do projeto. Fernanda, a diretora representante do poder público municipal, orgulhosamente nos contou: "O PROMETRÓPOLE introduziu uma nova forma de planejamento participativo, em que a população está envolvida desde a concepção do projeto". Ela ressaltou que essa forma de participação, introduzida pelo PT, diferiu dos procedimentos anteriores, que deram muito poder aos líderes comunitários estabelecidos e a suas organizações de base. Os representantes do PT viram essa abordagem antiga como não democrática e, em vez disso, aprovaram a participação mais direta da população local. Essa tendência "antiorganizacional” é típica do neoliberalismo (Weyland, 2003).

No entanto também se poderia ver essa tendência como uma estratégia deliberada do governo do PT para desestruturar líderes locais importantes e bem estabelecidos, muitos dos quais estavam ligados a outros partidos políticos (Koster, 2009; Nielsen, 2002). No entanto, mesmo que o PT tenha tentado neutralizar esses líderes locais influentes, vários deles foram eleitos para os novos comitês. Isso resultou numa situação em que a Prefeitura tentou se aliar com alguns deles na comunidade, evitando a interferência de outros mais exigentes. A atenção foi dada às queixas individuais, ao invés de dirigi-las às reivindicações coletivas. Um dos resultados disso foi um tratamento preferencial para aqueles que melhor pode- 
riam fazer ouvir sua voz nas reuniões, ou os que conseguiram estabelecer boas relações individuais com os representantes do projeto. Eles, muitas vezes, receberam tratamento preferencial, como aumento da compensação para o seu barraco demolido, ou uma casa melhor fora do projeto, ou uma localização melhorada na reconstrução. Em outras palavras, aqueles que agiram como cidadãos autônomos tiveram um tratamento melhor.

\section{OS EFEITOS ENFRAQUECEDORES DA CIDADANIA PARTICIPATIVA}

O discurso participativo empregado no PROMETRÓPOLE foi, muitas vezes, fundamental na ordenação dos moradores da favela para terem calma, esperarem e cooperarem (Nuijten, 2003). Eles foram orientados a colaborar e a não protestar, pois essa última atitude só atrapalharia o processo. Nas reuniões, a Prefeitura e as empresas de construção vieram com planos claros e mostraram pouca possibilidade ou vontade de deixar seu trabalho ser influenciado pela opinião da população. As plenárias públicas funcionaram, principalmente, como um espaço onde a população pode expor suas opiniões e expressar seus ressentimentos e sua irritação. O público, muitas vezes, expressou - suas preocupações fundamentais, como a de que eles não queriam deixar seus barracos, ou seus vizinhos dos quais viveram próximos por ฮี่ muitos anos, ou esperar um ano para receber i uma casa nova. No entanto, esses aspectos 今 do projeto não estavam abertos à discussão. i. Os moradores das favelas se tornaram muito emotivos e, especialmente, no início do projeto, muitos exclamaram que nunca iriam deixar suas casas no riacho. Alguns líderes comunitários eram temidos por sua língua afiada e seu poder de influência sobre os moradores locais, e, na opinião dos representantes, pela possibilidade de estragarem a atmosfera das reuniões.

Quando a tensão estava alta, o discurso participativo, muitas vezes, serviu para "facili- tar”, pelo menos em certa medida, a situação. Um bom exemplo disso foi quando, durante uma reunião acalorada com duas centenas de pessoas presentes, uma representante do PROMETRÓPOLE, que era conhecida como uma fervorosa defensora da abordagem participativa, tomou a palavra. Ela tinha o dom de envolver as pessoas com as palavras e silenciar protestos, dando às pessoas a ideia de que elas estavam sendo ouvidas e levadas a sério. Ela conseguiu captar a atenção de todos com um discurso claro, sem termos técnicos e conceitos abstratos. Na verdade, ela abordou os moradores da favela como se estivesse falando com crianças, começando com o esboço de um projeto fracassado e, teatralmente, perguntando aos presentes: "É isto que você quer?"

Muitos na plateia responderam: " $-N a ̃ o ! "$ "Tudo bem" - continuou ela — "então nós precisamos fazer isso juntos, não é?”

"-Precisamos!"

Após essa resposta, ela começou a enaltecer o elevado nível de participação das pessoas no projeto. Ela lembrou às pessoas de que as reuniões foram organizadas e as pesquisas realizadas a fim de ouvi-las. E argumentou: "Nós também viemos até vocês, batendo em suas portas, uma após outra, para falar com vocês, porque queríamos saber a sua opinião". A urbanista continuou seu discurso explicando que o Banco Mundial havia colocado muitas exigências participativas no projeto: "O Banco Mundial diz assim. Certo, eu quero dar-lhe um empréstimo, mas você deve provar que as comunidades querem este plano". Ela terminou seu discurso com a pergunta: "Vocês me entenderam?” Quando não veio nenhuma resposta imediata positiva, ela acrescentou: “Mais ou menos, não é?” Esse tipo de discurso participativo foi um aspecto importante do PROMETRÓPOLE. Em outra ocasião, uma forma diferente de manipulação foi utilizada pelo diretor municipal do projeto, que, muitas vezes, esteve presente nessas reuniões. Quando a população discordou de parte do projeto, ele a colocou sob pressão, dizendo: "Certo. Se você 
não concorda, então nada vai acontecer".

$\mathrm{Na}$ maioria das vezes, representantes do governo estavam apenas buscando a aprovação oficial da população, da qual precisavam para passar à próxima etapa. Essa aprovação significou a maioria das mãos levantadas durante a votação pública no final de uma reunião plenária, num momento em que a maioria das pessoas já havia saído, a menos que lanches e refrigerantes fossem prometidos para depois. Apesar das críticas, muitas vezes fortes, no final, as pessoas sempre tendiam a colaborar com as propostas da Prefeitura. Também deve ser notado que uma grande parte da população nunca compareceu às reuniões.

\section{A PROMESSA E A ESTÉTICA DA MODERNIDADE}

Alguém poderia perguntar por que a população demonstrou tão pouco interesse nos processos participativos, e por que as pessoas tendiam a colaborar com as propostas, mesmo que frequentemente discordassem delas. Há várias razões para isso. Primeiramente, a maioria dos habitantes sentia que não havia maneira alguma de poder influenciar o regime de ordenação espacial: as pessoas podiam falar, reclamar e protestar contra os planos, mas, no final, de uma forma ou outra, eles aconteciam de qualquer maneira. Então, para que frustrar o processo? Em segundo lugar, as famílias pobres gostaram do fato de serem consideradas no projeto e incluídas nos processos de desenvolvimento, e de não terem sido desconsideradas (Koster, 2009). Assim, acreditando que a remoção era inevitável, o que estava em jogo, para eles, era garantir a inclusão. Se tanto dinheiro ia ser gasto na área, não seria algo bom para eles serem incluídos nisso? Para as pessoas normalmente excluídas, as promessas de um futuro melhor são muito atraentes, mesmo que estejam cientes dos perigos possíveis envolvidos (Nuijten, 2004). Em terceiro lugar, as promessas da modernidade desempenharam um papel central no funcionamento do PROMETRÓPOLE. Imagens de novas casas e de ruas retas repercutiram como noções de progresso para os moradores das favelas. "A favela vai se transformar em uma cidade", ouvimos frequentemente. E "uma cidade" significa um lugar com estradas pavimentadas e canais em linha reta, em que uma boa vida pode ser vivida, um lugar "civilizado".

Gostaríamos de ir mais longe e afirmar que a principal raison-d'être de projetos como o PROMETRÓPOLE reside nas atrações tremendamente poderosas da modernidade (Scott, 1998). Isso se manifesta em ambas as formas: discursivas, como um quadro para dar sentido, e não discursiva, como a derrubada de barracos e a construção de casas de concreto. Através de técnicas foucaultianas de governo - procedimentos, instrumentos, táticas, tecnologias e discursos (Dean, 1999) - o programa se estabeleceu como uma manifestação da modernidade, como algo a se desejar. A ordenação espacial moderna apresenta uma determinada estética que alimenta as aspirações por progresso. Davis (2006, p. 98) afirma que a urbanização de favelas é realizada em nome do “progresso" e do “embelezamento". Valladares (2000) mostra como as considerações estéticas estiveram na base dos programas de desenvolvimento urbano no Brasil (cf. Pow, 2009 sobre a China). Favelas são consideradas feias e desorganizadas, não só pelas classes médias, mas também por seus próprios moradores. Esse Programa como foi apresentado durante as reuniões, transformaria a favela em algo moderno e bonito. Os moradores foram atraídos por essas promessas, que alimentavam o sonho de uma casa digna e própria.

A visão de estradas retas, canais e cais, além de casas limpas e de concreto foi ao encontro dos sentimentos suscetíveis da população das favelas, gerando fortes aspirações de um futuro melhor e de inclusão social com cidadania. Aqui, a renovação urbana moderna, como Berman (1982) argumenta, a par de suas forças destrutivas, também produz aspi- 
rações por melhoria. A consideração de Berman (1982) sobre a construção da via expressa do Bronx, em Nova Iorque, onde viveu quando criança, revela isso. Para abrir espaço para a via expressa, muitos edifícios de apartamentos tiveram de ser demolidos. A ordenação espacial moderna, fantasiada com o sonho americano de progresso e beleza, tocou a "identificação com o progresso, com a renovação e a reforma" dos moradores do Bronx. O projeto "estava destruindo nosso mundo, mas [...] parecia estar funcionando em nome de valores que nós mesmos abraçamos” (Berman, 1982, p. 295). Na verdade, a modernidade produz convenções que também são encontradas entre as pessoas que sofrem por elas (Gibson-Graham; Ruccio, 2001). As convenções sobre o que é "bom e desenvolvido" segregam os moradores das favelas como "ruins, subdesenvolvidos e atrasados”. Elas foram também reproduzidas pelos próprios moradores da favela, cuja expectativa era de que o projeto piorasse temporariamente suas vidas, mas havia a perspectiva de "serem modernos" no futuro.

\section{IMPLEMENTAÇÃO DO PROJETO: conflitos de ordenação espacial}

A realidade, no entanto, acabou por ser diferente. Em 24 de abril de 2008, o novo proసิ jeto habitacional foi inaugurado oficialmente. As famílias receberam as novas casas gratuiสี tamente, com a condição de não alugá-las ou ç vendê-las. A inauguração foi um acontecimen蚛 to político proeminente, com a participação do i. prefeito do Recife, o governador do Estado de \& Pernambuco, representantes do PROMETRÓके POLE e diversas outras autoridades A inauguração foi transmitida na televisão e, nos meses que se seguiram, as imagens do novo projeto habitacional foram regularmente utilizadas nas campanhas políticas do PT. No dia seguinte à inauguração, as famílias se mudaram para as novas casas. No entanto, logo ficou claro que grande parte de seus móveis não caberiam nelas. As casas eram pequenas: dois pavimentos de $19 \mathrm{~m}^{2}$ cada, incluindo uma cozinha e um banheiro. Os barracos no riacho eram primitivos, mas eles eram, por vezes, bastante extensos, muito maiores do que as novas casas. As pessoas também ficaram irritadas com a falta de cercas e de grades nas janelas, as quais, a seu ver, eram necessárias para protegê-las da violência recorrente.

Havia outras razões para os habitantes estarem chateados com suas novas condições de habitação. O comportamento "civilizado" que se esperava colidiu com o estilo de vida de muitas famílias. No novo projeto habitacional, havia pouco ou nenhum espaço para guardar suas carroças, e as pessoas não estavam autorizadas a recolher e separar o lixo para reciclagem, que era o principal meio de renda para muitas famílias. Além disso, as novas casas não tinham quintais, por terem sido construídas com os fundos próximos uns dos outros, e nem oitões, ou paredes laterais, por serem conjugadas em ambos os lados. Isso foi problemático, porque quintais desempenham uma função importante para muitas atividades domésticas e profissionais. A pecuária não era permitida no novo projeto habitacional, o que foi mais um problema para muitas famílias. Assim, a ordenação espacial da nova área de habitação não correspondeu aos modos de vida dos moradores das favelas. Além disso, as casas eram inadequadas para famílias grandes. Ademais, antes, no Jacarezinho, eles aproveitavam ilegalmente a água e a eletricidade, mas tinham agora de pagar, algo que os mais pobres não tinham condições de fazer.

Isso explica por que, como já ocorreu em projetos semelhantes, uma parte da população nunca se estabeleceu em suas novas casas, mas partiu para ir morar em outro lugar, ocupando outros locais da cidade. Essas pessoas alugaram ou venderam suas casas, transações formalmente proibidas. Correram boatos de que casas estavam sendo vendidas por R\$3.000, embora seu valor estivesse estimado em R\$23.000. Outras famílias imediatamente começaram a ven- 
der tudo que podiam remover da casa, desde a escada de metal até o banheiro e o lavatório.

As pessoas que permaneceram nas casas logo começaram a transformar a concepção do espaço urbano que lhes havia sido imposta. Elas personalizaram e demarcaram suas próprias casas. Construíram muros altos e cercas como medidas de segurança para protegerem-se do meio altamente violento. Ampliaram suas casas e construíram alpendres quando tinha recursos para fazê-lo. Apropriaram-se de partes de calçadas e ruas, tiraram a maioria das árvores recém-plantadas e mudaram o plano da praça central.

Os burocratas do PROMETRÓPOLE ficaram horrorizados com o que viram quando da destruição de seu projeto. Eles visitaram frequentemente a área e advertiram as pessoas de que não estavam autorizadas a modificar suas casas. Várias reuniões foram convocadas para informar sobre os procedimentos oficiais que tinham de ser seguidos para construções novas e reconstruções na nova moradia. Isso não teve sucesso, e o conjunto habitacional novo logo parecia um canteiro de obras, com tijolos, concreto e montes de areia por toda parte, com todos construindo a partir de seu próprio gosto. Na opinião dos representantes do PROMETRÓPOLE, as intervenções feias, construídas pelos próprios habitantes, destruíam o modelo cuidadosamente projetado dos arquitetos, transformando o local, de novo, em uma favela. A maioria desses representantes culpa os baixos valores morais e o atraso cultural dos moradores da favela pelos problemas com as novas moradias. $\mathrm{O}$ projeto incluiu a instrução da população sobre o uso "adequado" das casas novas e o cuidado com os espaços públicos, e também como um cidadão "adequado" deve lidar com seus vizinhos e cuidar das árvores e plantas do projeto. No entanto, com apenas algumas crianças e a presença de uma ou duas mulheres, o comparecimento a essas sessões de treinamento foi extremamente baixo. Os representantes do projeto ficaram horrorizados, porque, os moradores das favelas não se com- portam como beneficiários agradecidos e não se adaptam às visões modernistas sobre o uso do espaço. Um deles, desesperadamente, exclamou: "Eles não obedecem”. Em sua opinião, por arruinar a estética do projeto modernista, os moradores das favelas estão se recusando a se tornar cidadãos decentes.

No entanto, em nossa opinião, esse projeto tentou impor uma visão de ordenação espacial "civilizada", aquela em que "os outros subdesenvolvidos” são considerados impróprios para tal. Na realidade, as verdadeiras causas da pobreza e da exclusão não foram abordadas nesse projeto. A dúvida é como uma casa nova pode resolver os problemas de discriminação, desemprego e violência relacionada às drogas, que são as principais preocupações da população. Quando indagados sobre essas questões, os responsáveis locais aceitaram, imediatamente, que os problemas da desigualdade social no Brasil são imensos, bem como a falta de oportunidades para os pobres, mas destacaram que o projeto PROMETRÓPOLE não visa a solucionar esses problemas. Eles entenderam muito bem por que algumas famílias decidiram vender ou alugar sua nova casa, em vez de viver nela. Ao mesmo tempo, eles estavam desapontados com o fato de os pobres, ao se apropriarem do espaço de forma diferente, não o fazerem da forma "apropriada".

\section{CONCLUSÕES: regimes de orde- nação espacial e reapropriação do espaço urbano}

Em todo o mundo, têm proliferado mecanismos nacionais e internacionais envolvidos na urbanização e remoção de favelas, muitas vezes em nome dos pobres. Como o espaço é fundamental para a identidade e para os meios de vida das pessoas, a reconstrução espacial tem enormes implicações para a população-alvo. Isso é especialmente verdadeiro, pois projetos habitacionais como esses afetam as pessoas em seus domínios mais privados. 
Como todos os modelos incorporam valores, toda concepção espacial é, de alguma forma, política (Weber, 2010). Apesar disso, os projetos de urbanização de favelas minimizam a dimensão política de seu modelo e tendem a ignorar o uso do espaço pelos pobres e os possíveis efeitos perturbadores das intervenções.

Neste artigo, discutimos o projeto de urbanização PROMETRÓPOLE, no Recife, Brasil, financiado pelo Banco Mundial. Nós mostramos que esse projeto apresenta uma notável fusão de uma abordagem neoliberal, com a política socialista do PT e uma concepção modernista do espaço urbano. Introduz novas responsabilidades público-privadas na urbanização de favelas, obrigando seus moradores a cuidarem de suas próprias vidas e dos arredores, a estabelecerem relações individuais com os órgãos governamentais sobre o tema da reorganização espacial, a se envolverem ativamente em processos participativos e a usarem o espaço público e privado de acordo com pontos de vista de ordem e vida civilizada da classe média.

Essa fusão de ideais, como vimos, é muito poderosa para fazer do espaço urbano um alvo de intervenção e imposição de conceitos disciplinares sobre a população. Os programas de urbanização de favelas como o PROMETRÓPOLE demarcam grupos de pessoas através da definição de zonas físicas de inter$\sim$ venção. Seja quem for que viva dentro dessas సิ zonas, de repente é considerado como um "objeto de melhoria” e incorporado em programas ํ. disciplinares, destinados a criar uma ordem 尺̄ moderna e cidadãos "decentes". Um objetivo 各 emancipatório implícito de muitos projetos de ì urbanização de favelas é "civilizar" os pobres

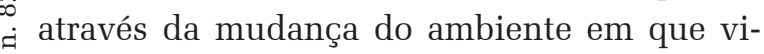
mे vem. No PROMETRÓPOLE, treinamento es-

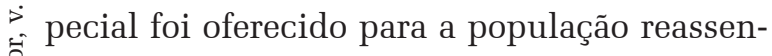
tada, exemplificando como a ordenação espacial, através do planejamento urbano, envolve processos formativos que tentam criar sujeitos urbanos adequados (Rabinow, 2003).

Nosso estudo revelou uma incompatibilidade clara entre os objetivos e procedimentos do projeto, por um lado, e as necessidades e os meios de vida da população, por outro. Poder-se-ia argumentar que tais projetos de urbanização de favelas, em vez de olhar para aquilo de que os pobres precisam, exigem que eles se integrem à sociedade, sigam as normas da classe média sobre como se comportar e usar o espaço, mas sem os empregos, o dinheiro e sem outros requisitos para a manutenção desse estilo de vida. Eventualmente, como consequência, muitas pessoas não têm outra opção a não ser deixar suas moradias novas e ir construir um barraco em outra área de terra desocupada. Dessa forma, os programas de urbanização de favelas tendem a causar diferenciação entre os pobres urbanos, expulsando os mais pobres (Davis, 2006).

$\mathrm{O}$ enfoque neoliberal do projeto sobre a autorrealização dos pobres, com a necessidade de que eles cuidem de suas próprias vidas, possui uma dimensão perversa, uma vez que essas pessoas pertencem ao segmento da humanidade que é supérfluo à ordem política e econômica presente (Bauman, 2003). Os moradores, que sempre foram marginalizados pelo funcionamento excludente das instituições oficiais, são agora "fortalecidos" por elas, com a responsabilidade de cuidar de si mesmos, mas sem receber qualquer meio de fazê-lo. Então, se suas vidas não mudarem para melhor, eles são os culpados por isso.

Embora tenhamos sido inspirados por teorizações foucaultianas sobre dominação e hegemonia, também mostramos que houve aspectos menos deterministas da urbanização de favelas do que aberturas criadas para as práticas e as experiências vividas dos moradores (Koster; Vries, 2012). O artigo mostra como, apesar de o regime de ordenação espacial deixar pouco espaço para manobra, a população mostrou inúmeras formas com as quais poderiam se reapropriar do espaço urbano de acordo com as suas próprias necessidades e desejos (Low, 1996) e "encontrar formas de representar seu próprio sentido de lugar” (Sheller, 2009, p. 199). Os representantes do projeto consideraram essas formas "locais" de utilização 
do espaço como uma contestação do projeto e uma forma de subversão dos "incivilizados" (Lefebvre, 1991). Baseando-se em noções de estratégia e tática de Michel de Certeau (1984), podemos dizer que, embora o espaço urbano seja moldado através da concepção e planos de "estratégias", também é "reformulado" através das "táticas", muitas vezes clandestinas e oportunistas, dos moradores da favela. Através dessas "táticas", eles lidam com a situação que enfrentam, contestando ou, pelo menos, evitando as forças disciplinares das estratégias inerentes ao regime de renovação urbana (Low, 1996). Isso, como já vimos, leva a um confronto entre diferentes lógicas de ordenação espacial, quando o mundo dos pobres urbanos encontra o mundo utópico dos urbanistas - quando as pessoas marginalizadas "encontram" o projeto modernista. O projeto PROMETRÓPOLE, no Jacarezinho, ilustra como a luta para ganhar e recuperar o controle sobre o espaço se tornou realmente um objeto central da luta política no mundo contemporâneo (Brenner, 2000).

Recebido para publicação em 06 de dezembro de 2017 Aceito em 31 de janeiro de 2018

\section{REFERÊNCIAS}

AGUIRRE, A.; EICK, V.; REESE E. Introduction: neoliberal globalization, urban privatization, and resistance. Social justice, v. 33, n. 3, p. 1-5, 2006.

ALVITO, M. As cores de Acari: uma favela carioca. Rio de Janeiro: Editora FGV, 2001.

ASSIES, W. Neighborhood associativism in: Recife, 19641988. Amsterdam: CEDLA, 1992.

BAIOCCHI, G. Emergent public spheres: talking politics in participatory governance. American sociological review, v. 68, n. 1, p. 52-74, 2003.

BAUMAN, Z. Wasted lives: modernity and its outcasts. Cambridge: Polity press, 2003.

BERMAN, M. All that is solid melts into air: the experience of modernity. New York: Penguin Books, 1982.

BITOUN, J. et al. Orçamento participativo em Recife: gestão do planejamento, exercício de cidadania. Recife: FASE Pernambuco, 2002.

BRENNER, N. The urban question as a scale question: reflections on Henri Lefebvre, urban theory and the politics of scale. International journal of urban and regional research, v. 24, n. 2, p. 361-378, 2000.

BRENNER, N.; THEODORE, N. Cities and the geographies of "actually existing Neoliberalism". Antipode, v. 34, n. 3, p.349-379, 2002.

CALDEIRA, T.; HOLSTON, J. State and urban space in Brazil: from modernist planning to democratic interventions. In: ONG, A.; COLLIER, S. J. (Ed.). Global anthropology: technology, governmentality, ethics. London: Balckwell publishers, 2005. p. 393-416.

CERTEAU, M. de. The practice of everyday life. Berkeley: University of California Press, 1984.

CONDEPE FIDEM. Agência Estadual de Planejamento e Pesquisas de Pernambuco. 2007. Disponível em: <www. condepefidem.pe.gov.br>. Acesso em: 26 jan. 2017.

COP. Conselho Municipal de Gestão Democrática do Orçamento Público. Recife: [S.n.], 2002.

CORREIA, J. T. de L. Hidden meanings: the mocambo. Recife. Social science information, v. 38, n. 2, p. 297-327, 1999

CABRAL, A. A. C. Reassentamentos de moradias populares: controle social, justiça social-territorial ou produção do espaço de cidadania (1980 a 2012): o caso da comunidade Chão de Estrelas - Recife/PE (Brasil). 2003. 359 f. Tese (Doutorado em Geografia) - Centro de Filosofia e Ciências Humanas, Recife, 2013.

DALSGAARD, A. L. Matters of life and longing: female sterilisation in Northeast Brazil. Copenhagen: Museum Tusculanum Press, 2004.

DAVIS, M. Planet of slums. London: Verso, 2006

DEAN, M. Governmentality: power and rule in modern society. London: Sage, 1999.

ETAPAS. Gestão participativa no Recife: do Prezeis ao Orçamento participativo. In: ENCONTRO DA RPA6 - H3, 2003, Recife. Anais... Recife: ComunicaçãoVisual, 2003.

FASE; CENDHEC; URB. PREZEIS: Manual para lideranças. Recife: Fase, 1997.

FULLER, C.; GEDDES, M. Urban governance under Neoliberalism: new labour and the Restructuring of StateSpace. Antipode, v. 40, n. 2, p. 252-282, 2008.

GIBSON-GRAHAM, J. K.; RUCCIO, D. "After development": Re-imagining economy and class. In: GIBSON-GRAHAM, J. K.; RESNICK, S.; WOLFF, R. D. (Ed.). Re/presenting class: Essays in Postmodern Marxism. Durham: Duke University Press, 2001. p 158- 181

GOLDSTEIN, D. Laughter out of place: race, class, violence, and sexuality in a Rio Shantytown. Berkeley: Los Angeles: University of California Press, 2003.

HOLSTON, J. Insurgent citizenship: disjunctions of democracy and modernity in Brazil. Princeton: Princeton University Press, 2008.

IBGE. Censo demográfico 2010. 2010. Disponível em: <http://www.ibge.gov.br/home/estatistica/populacao/ censo2010/PE2010.pdf>. Acesso em: 23 nov. 2010.

KOSTER, M. In fear of abandonment: slum life, community leaders and politics in Recife, Brazil. 2009. Thesis (PhD) Wageningen University, [S.l.], 2009.

KOSTER, M.; NUIJTEN, M. From Preamble to Post-Project Frustrations: The Shaping of a Slum Upgrading Project in Recife, Brazil. Antipode, v. 44, n. 1, p. 175-196, 2012.

KOSTER, M.; VRIES P. Slum politics: community leaders, everyday needs and utopian aspirations in a Recife slum, Brazil. Focaal, v. 62, p. 83-98, 2012.

LARNER, W.; CRAIG, D. After Neoliberalism? Community activism and local partnerships in Aotearoa New Zealand. Antipode, 373: 402-424, 2012.

LEAL, S. Fetiche da participação popular: novas práticas de planejamento, gestão e governança democrática no 
Recife - Brasil. Recife: CEPE, 2003.

LEFEBVRE, H. The production of space. Oxford: Blackwell, 1991.

LOW, S. Spatializing culture: the social production and social construction of public space in Costa Rica. American Ethnologist, v. 23, n. 4, p. 861-879, 1996.

LEITE, S. de P. B. R. Participação popular e acesso à moradia: as escolhas possíveis para a população removida por intervenções de melhoria urbana do PREZEIS. Recife: Ed. Universitária da UFPE, 2007.

MAIA, M. Land use regulations and rights to the city: squatter settlements in Recife, Brazil. Land use policy, v. 12, n. 2, p. 177-180, 1995.

MIGUEL, L. F. From equality to opportunity: transformations in the discourse of the Workers' Party in the 2002 elections. Latin American perspectives, v. 33, n. 4, p. 122-143, 2002.

NIELSEN, M. Contesting the moralities of leadership: the consequences of participatory politics for the local understandings and performance of moral neighbourhood leadership in a poor urban area in the northeast of Brazil. 2002. MSc (thesis) - Institute of Antrhopology, University of Copenhagen, [S.1.], 2002.

NUIJTEN, M. Power, community and the state: the political anthropology of organisation in Mexico. London: Pluto Press, 2003.

. Between fear and fantasy: governmentality and the working of power in Mexico. Critique of Anthropology, v. 24, n. 2, p. 209-230, 2004.

ORÇAMENTO PARTICIPATIVO (OP). 2011. Disponível em: < www.recife.pe.gov.br/op>. Acesso em: 29 mar. 2011.

PECK, J.; TICKELL, A. Neoliberalizing Space. Antipode, v. 34, n. 3, p. 380-404, 2002.

Conceptualizing neoliberalism, thinking Thatcherism. In: LEITNER, H.; PECK, J.; SHEPPARD, E. S. (Ed.). Contesting Neoliberalism: urban frontiers. New York: Guilford, 2007. p. 26-50.

PERLMAN, J. The myth of marginality: urban poverty and politics in Rio de Janeiro. Berkeley: Los Angeles: University of California press, 1976.

POW, C.-P. Neoliberalism and the aestheticization of new middle-class landscapes. Antipode, v. 41, n. 2, p. 371-390, $\infty 2009$
RABINOW, P. Ordonnance, discipline, regulation: some reflections on urbanism. In: LOW, S.; LAWRENCEZUNIGA, D. (Ed.). The anthropology of space and place: locating culture. Oxford: Blackwell, 2003. p. 353-362.

RILEY, E.; FIORI, J.; RAMIREZ, R. Favela bairro and a new generation of housing programmes for the urban poor. Geoforum, v. 32, p. 521-531, 2001.

SCHEPER-HUGHES, N.; BOURGOIS, P. Foreword to goldstein D. Laughter out of place: Race, Class, Violence, and sexuality in a Rio Shantytown. Berkeley: Los Angeles: University of California press, 2003. p. 13-17.

SCHWEGLER, T. A. Take it from the top (down)? Rethinking Neoliberalism and political hierarchy in Mexico. American Ethnologist, v. 35, n. 4, p. 682-700, 2008.

SCOTT, J. Seeing like a state: how certain schemes to improve the human condition have failed. New Haven: London: Yale University Press, 1998.

SHELLER, M. The new Caribbean complexity: mobility systems, tourism and spatial rescaling. Singapore journalof tropical Geography, v. 30, p. 189-203, 2009.

SOUSA, A. de. Do mocambo a favela. Recife 1920-1990. Joao Pessoa: Editora Universitária, 2003.

SOUZA, F. de. The future of informal settlements: lessons in the legalization of disputed urban land in Recife, Brazil. Geoforum, v. 32, p. 483-492, 2001.

Security of land tenure revised: the case of CRRU in: Recife and Porto Alegre, Brazil. Habitat international, v. 28, p. 231-244, 2004.

TEIXEIRA, A $\mathrm{C}$ et al. Orçamento participativo: democratização da gestão pública e controle social: as experiências de participação popular na aplicação do dinheiro público municipal. Rio de Janeiro: FASE, 2004.

VALLADARES, L. A gênese da favela carioca: a produção anterior às ciências sociais. Revista brasileira de Ciências Sociais, v. 15, n. 44, p. 5-34, 2000.

WEBER, C. Introduction: design andcitizenship. Citizenship studies, v. 14, n. 1, p. 1-16, 2010.

WEYLAND, K. Neopopulism and neoliberalism in Latin America: how much affinity? Third

world quarterly, v. 24, n. 6, p. 1095-1115, 2003

WORLD BANK. Report no: 23331-BR: Project appraisal document on a proposed loan in the amount of US\$46.0 million to the state of Pernambuco, Brazil, with the guarantee of the Federal Republic of Brazil for the Recife urban upgrading project. [S.1.: S.n.], 2003. 
REGIMES OF SPATIAL ORDERING IN BRAZIL: neoliberalism, leftist populism and modernist aesthetics in slum upgrading in Recife

\section{Monique Nuijten, Martijn Koster, Pieter de Vries Augusto Antonio Campelo Cabral}

This article shows how regimes of spatial ordering are produced by the entangling of neoliberalism, leftist populism and modernist visions. It focuses on Prometrópole, a slum upgrading project in Recife. In this project, the neoliberal dimension manifests in the idea that the state, private companies and citizens together are responsible for (re)constructing urban space, and that beneficiaries are autonomous citizens, taking responsibility for their new living environment. The leftist political dimension is seen in participatory procedures to involve the residents in the project. The modernist aesthetics informs the project design with the requirement to use the new space according to the standards of "modern civilization". As our research shows, such a regime of spatial ordering clashes with the livelihoods of the residents. Furthermore, the participatory procedures fail to grant them any real influence in creating their environment. Consequently, these residents drastically reconstruct their estate, reappropriating the urban space and contesting the regime imposed upon them.

KEY wORDS: Favelas Urbanization. Urban Space. Participation. Neoliberalism. Socialism.
LES RÉGIMES D'ORDONNANCEMENT SPATIAL AU BRÉSIL: la fusion du Néolibéralisme, du populisme de gauche et des visions modernistes dans l'urbanisation des favelas à Recife

\author{
Monique Nuijten, Martijn Koster, Pieter de Vries \\ Augusto Antonio Campelo Cabral
}

Cet article montre comment, au Brésil, les régimes d'ordonnancement spatial sont produits par la jonction de trois forces: le néolibéralisme, la politique de gauche et les visions modernistes. Il se concentre sur le PROMÉTROPOLE, Programme d'Infrastructures dans les Aires à Faible Revenus de la Région Métropolitaine de Recife, programme financé par la Banque Mondiale. Dans ce projet, la dimension néolibérale est claire quant à l'idée que l'État, les entreprises privées et les citoyens sont conjointement responsables de la construction de l'espace urbain. En outre, on attend des bénéficiaires qu'ils se comportent comme des citoyens autonomes et qu'ils assument la responsabilité de leur nouvel environnement de vie. D'un autre côté, la dimension politique de la gauche nourrit l'idée que, grâce à des procédures participatives, le gouvernement devrait permettre à la population cible de prendre part au projet de sa conception à sa mise en œuvre. En échange on espère que les habitants maintiendront une relation de coopération avec le gouvernement. La troisième dimension consiste en l'adoption d'une esthétique moderniste - lignes droites, espaces ouverts et ordre visible - qui configure la conception du projet. L'exigence du gouvernement est que les habitants des favelas utilisent leurs maisons et leurs espaces publics selon les normes de la "civilisation moderne". Cependant cette recherche montre que ce régime d'ordonnancement spatial entre en conflit avec les modes de vie de la population urbaine pauvre qui peut même voir sa qualité de vie se détériorer à cause de ce genre d'intervention. De plus, contrairement à ce qui est affirmé, les procédures participatives ne permettent pas à la population cible d'avoir une véritable influence. Au final, les résidents reconstruisent résolument les espaces privés et publics des nouveaux quartiers résidentiels, en reprenant ainsi possession de cet espace urbain et en contestant le régime d'ordonnancement spatial qui leur est imposé.

Mots-CLÉS: Urbanisation des Favelas. Espace Urbain. Participation. Néolibéralisme. Socialisme.

\begin{abstract}
Monique Nuijten - Doutora em Sociologia do Desenvolvimento pela Wageningen University, Holanda. Os seus interesses de pesquisa incluem, Estado e poder local, projetos de desenvolvimento, organização de base e política popular. Ela realizou pesquisas no México, Peru, Brasil e na Espanha. Ela é professora de antropologia política no Departamento de Sociologia de Desenvolvimento e Cambio na Wageningen University, Holanda. Atualmente, ela coordena o projeto de pesquisa "Agencia política de base: movimentos sociais y ativismo político".

Martijn Koster - Doutor em Sociologia do Desenvolvimento pela Wageningen University, Holanda (2009). Os seus interesses de pesquisa incluem governança urbana participativa, cidadania, exclusão social, política informal e planejamento urbano. Ele realizou pesquisas no Brasil e na Holanda. Ele é professor no Departamento de Antropologia e Estudos de Desenvolvimento na Radboud University Nijmegen, Holanda. Atualmente, ele coordena o projeto de pesquisa "Governança urbana participativa entre democracia e clientelismo", financiado pelo European Research Council. O programa inclui estudos no Brasil, Colômbia, Inglaterra e Holanda.

Pieter de Vries - Doutor em Ciências Agrícola na Wageningen University. Trabalha com temas relacionados à intermediação politica e desenvolvimento urbano e desenvolvimento desde uma perspectiva lacaniana/deleuziana; Publicou, entre outros textos os artigos Comunidad y desarrollo en los Andes Peruanos. Una crítica etnográfica al programa de modernidad/ colonialidad. Sociologias, 15(33), em 2013 e 'The inconsistent city, participatory planning, and the part of no part in Recife, Brazil'. Antipode, 48(3), 790-808, em 2017.

Augusto Antonio Campelo Cabral - Doutor em Geografia (Geografia Humana), com área de concentração em Regionalização e Análise Regional pela Universidade Federal de Pernambuco UFPE, Brasil. Foi professor no Curso de Pós-graduação em Educação Ambiental, realizada pela Autarquia Educacional de Serra Talhada em parceria com o Instituto Superior de Educação de Salgueiro (2005) e professor na Faculdade Decisão FADE - PE (2012). Atualmente é docente efetivo da Secretaria de Educação de Pernambuco, lotado na Escola de Referência em Ensino Médio Santa Paula Frassinetti (2015).
\end{abstract}

